\title{
Combinação de Técnicas para Harmonização Orofacial em Paciente Jovem: Relato de Caso
}

Combinación de Técnicas de Armonización Orofacial en Paciente Joven: Reporte de Caso

Combination of Orofacial Armonization Techniques in Young Patient: Case Report

Marcela Filié HADDAD

Cirurgiã-Dentista, Mestre e Doutora em Prótese, Professora da disciplina de Prótese Total Removível da Faculdade de Odontologia, Universidade Federal de Alfenas (UNIFAL-MG), 37.130-000 Alfenas - MG, Brasil https://orcid.org/0000-0003-3455-6624

Isadora Bernardes DA SILVA

Cirurgiã(o)-Dentista graduada(o) pela Faculdade de Odontologia, Universidade Federal de Alfenas (UNIFAL-MG),

37.130-000 Alfenas - MG, Brasil

Luiz Ricardo Santos OLIVEIRA

Cirurgiã(o)-Dentista graduada(o) pela Faculdade de Odontologia, Universidade Federal de Alfenas (UNIFAL-MG),

37.130-000 Alfenas - MG, Brasil

Ítalo Augusto Silva FERREIRA

Aluno do Curso de graduação em Odontologia, Faculdade de Odontologia, Universidade Federal de Alfenas (UNIFALMG), 37.130-000 Alfenas - MG, Brasil

\section{Resumo}

Introdução: Considerando-se os padrões estéticos impostos pela sociedade atual e o número crescente de procedimentos que visam a harmonia e as proporções das estruturas faciais, a visão ampliada da odontologia, considerando toda a estrutura orofacial além dos dentes, torna-se de extrema importância. Objetivo: O objetivo deste trabalho é relatar um caso clínico de harmonização orofacial em paciente jovem. Relato de caso: Na execução do presente caso, foram combinadas três técnicas: microagulhamento para melhora da textura da pele; aplicação de toxina botulínica tipo A, para amenizar marcas de expressão dinâmicas e relaxar a musculatura do mento, área de interesse para a alteração de perfil; e limitar o movimento do lábio superior, reduzindo o sorriso gengival; e aplicação de ácido hialurônico na região de mento e da deformidade do canal lacrimal. Conclusão: Após o tratamento, o perfil da paciente ficou mais harmônico e a mesma relatou grande satisfação estética e melhora da autoestima.

Descritores: Ácido Hialurônico; Face; Toxinas Botulínicas Tipo A.

Abstract

Introduction: Considering the aesthetic standards imposed by today's society and the growing number of procedures aimed at harmony and proportions of facial structures, the expanded vision of dentistry, considering the entire orofacial structure in addition to the teeth, becomes extremely important. Objective: The aim of this paper is to report a clinical case of orofacial harmonization in a young patient. Case report: In carrying out this case, three techniques were combined: microneedling to improve skin texture; application of botulinum toxin type A, to alleviate dynamic expression marks and relax the muscles of the chin, an area of interest for changing the profile; and limit the movement of the upper lip, reducing the gummy smile; and application of hyaluronic acid in the chin and lacrimal duct deformity region. Conclusion: After treatment, the patient's profile became more harmonious and she reported great aesthetic satisfaction and improved self-esteem.

Descriptors: Hyaluronic Acid; Face; Botulinum Toxins, Type A.

\section{Resumen}

Introducción: Teniendo en cuenta los estándares estéticos impuestos por la sociedad actual y el creciente número de procedimientos dirigidos a la armonía y proporciones de las estructuras faciales, la visión ampliada de la odontología, considerando toda la estructura orofacial además de los dientes, cobra suma importancia. Objetivo: El objetivo de este trabajo es reportar un caso clínico de armonización orofacial en un paciente joven. Caso clínico: En la realización de este caso se combinaron tres técnicas: microagujas para mejorar la textura de la piel; aplicación de toxina botulínica tipo A, para aliviar las marcas de expresión dinámica y relajar la musculatura del mentón, área de interés para cambiar el perfil; y limitar el movimiento del labio superior, reduciendo la sonrisa gingival; y aplicación de ácido hialurónico en la región de la deformidad del mentón y del conducto lagrimal. Conclusión: Después del tratamiento, el perfil de la paciente se volvió más armonioso y reportó una gran satisfacción estética y una mejor autoestima.

Descriptores: Ácido Hialurónico; Cara; Toxinas Botulínicas Tipo A

INTRODUÇÃO

\section{A beleza é entendida como algo}

subjetivo e pessoal e que pode variar de acordo com a cultura, raça, etnia, por influência de familiares e pessoas próximas, necessidade da aceitação popular e sobre o contexto atual do que está na moda e exposto nas mídias ${ }^{1}$. As alterações estéticas faciais e a insatisfação com a autoimagem têm acarretado em visões negativas sobre a vida do indivíduo, com possíveis agravamentos de problemas biopsicossociais, comprometendo sua autoestima, posicionamento dentro da sociedade e qualidade de vida, pela presença de sentimentos de inferioridade, não aceitação e impotência ${ }^{2}$. Por esse motivo, o entendimento dessas questões e a escuta das insatisfações do paciente quanto à sua imagem são essenciais pelos médicos e cirurgiões dentistas nos procedimentos estéticos orofaciais ${ }^{3}$.

Em razão disto, a visão ampliada da odontologia, considerando toda a estrutura orofacial além dos dentes, torna-se de extrema importância ${ }^{4}$. A favor desta ideia, foi aprovado no ano 2019, pela resolução do Conselho Federal de Odontologia (CFO) CFO198/20195 , o reconhecimento da Harmonização Orofacial (HOF) como especialidade odontológica. A HOF representa um conjunto de técnicas $e$ procedimentos aplicados visando à correção e/ou suavização de assimetrias faciais, harmonizando traços e linhas do rosto de acordo com a individualidade de cada paciente, preservando suas características ${ }^{4}$.

O microagulhamento é um dos procedimentos que compõem a gama de opções para preparo da pele em harmonização orofacial. Para sua realização são utilizadas diversas agulhas esterilizadas de aço cirúrgico, dispostas em um rolo (dermaroller) ou caneta (dermapen), que é aplicado na pele, provocando pequenas microperfurações, que aumentam a vasodilatação, induzindo a formação de colágeno provendo a renovação da pele, sendo 
possível amenizar a aparência de cicatrizes, marcas de acne, além de reorganizar as fibras internas, deixando a pele mais firme e com mais vitalidade, aumentando a absorção de alguns medicamentos de forma concentrada, 0 chamado drug delivery ${ }^{6}$.

Outro recurso bastante conhecido é a aplicação de toxina botulínica, que tem emprego funcional de grande importância dentro da Odontologia, podendo ser utilizada como opção ou coadjuvante aos tratamentos odontológicos convencionais para quadros de disfunção temporomandibular, espasmo hemimastigatório, bruxismo e sialorreia ${ }^{7}$ e, em termos de estética, pode ser empregada na prevenção ou suavização das marcas de expressão e também na limitação dos movimentos dos músculos envolvidos na elevação do lábio, amenizando o sorriso gengival ${ }^{4}$. Sua aplicação é caracterizada por se tratar de um procedimento que demanda de tempo clínico curto, ser pouco invasivo, reversível, com boa relação custo-benefício, durabilidade satisfatória (entre 120 e 180 dias, em média) e, apesar destas vantagens, ainda conseguir solucionar 0 problema muscular apresentado pelo paciente ${ }^{7,8}$.

Já o preenchimento com ácido hialurônico é realizado para conferir ou restaurar o volume perdido em regiões da face. Seu comportamento biológico é bem conhecido, sendo absorvido gradativamente ao longo dos meses. É de extrema importância observar a reação do organismo após a aplicação de ácido hialurônico na face, pois os eventos adversos imediatos e precoces (como, por exemplo, a possibilidade de embolização) geralmente se manifestam com uma inflamação leve, dor com sensibilidade no local da aplicação, hematomas e eritemas que podem variar de intensidade e duração, quando os eventos tardiamente acontecem, os sintomas são complexos, podendo apresentar nódulos, encapsulamento do produto, hipercorreção tecidual e necrose ${ }^{3,9}$.

$\mathrm{Na}$ busca pela beleza, uma porção de importante do rosto que ajuda a promover a harmonização facial é o terço inferior, ocupado em grande parte pelo mento. $\mathrm{O}$ preenchimento desta região, quando bem indicado e executado, tem 0 poder de equilibrar as proporções entre os terços faciais, se tornando uma opção viável para pacientes que apresentem como queixa principal a pouca evidência do mento na observação do perfil e não estão dispostos ou estão impossibilitados de se submeterem a tratamentos ortodônticos longos e/ou procedimentos cirúrgicos mais invasivos ${ }^{10}$.

A análise facial por muito tempo tem sido usada por cirurgiões bucomaxilofaciais e ortodontistas. Ela ajuda no diagnóstico e na condução do tratamento. Hoje, com a regulamentação da execução dos procedimentos envolvidos com a HOF por cirurgiões-dentistas, cada vez mais profissionais da área buscam esse conhecimento. Saber os fundamentos da análise facial permite diagnosticar a desarmonia e identificar se sua origem é dentária, muscular, esquelética ou devido à alteração anatômica. Assim, o cirurgião-dentista consegue ponderar se 0 tratamento pode ser feito com terapias estéticas não invasivas ${ }^{11}$.

O objetivo do presente relato é apresentar um caso clínico de harmonização facial de paciente jovem envolvendo três técnicas: microagulhamento, aplicação de toxina botulínica tipo $A$ e preenchimento com ácido hialurônico.

CASO CLÍNICO

Inicialmente, a paciente de 27 anos, sexo feminino, leucoderma, procurou atendimento na clínica de prótese da Faculdade de Odontologia, queixando-se de linhas de expressão finas, sorriso gengival, deficiência do terço inferior da face e olheiras pronunciadas.

Foi realizada anamnese, exame clínico e registro fotográfico da paciente (Figura 1). Durante estas etapas, foi notado que ela apresentava uma boa textura de pele, porém, realmente eram evidentes linhas finas estáticas, filtro labial pouco delimitado, olheiras profundas, além do excesso de força para selamento labial, caracterizado pelo aspecto de casca de laranja no mento (Figura 1A). Foram observadas, também, linhas dinâmicas mediante as expressões faciais (Figuras 1B-D), especialmente na região dos músculos frontal (Figura 1B), prócero e corrugadores do supercílio (Figura 1C) e na área periocular (Figura 1D). Ficou evidente grande exposição de gengiva durante 0 sorriso forçado (Figura 1D) e deficiência de terço inferior da face, o que promovia um perfil convexo à paciente (Figura 1E).

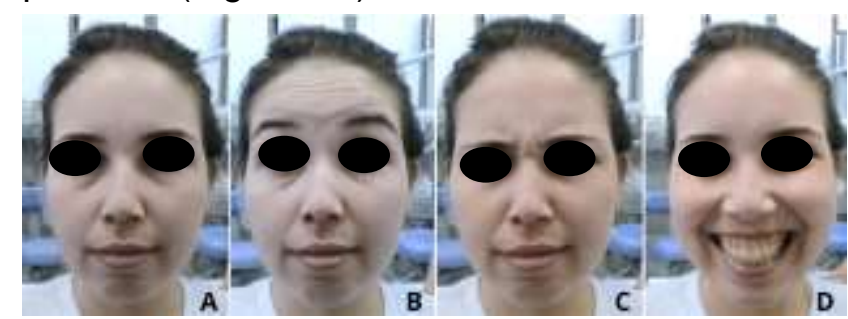

Figura 1 - Imagens inicias da paciente em repouso (A), com expressões faciais ( $B$ a $D$ ), apresentando rugas dinâmicas na região frontal $(B)$; de prócero e corrugadores de supercílio (C) e na região periorbicular, além de sorriso gengival (D); e perfil (E) caracterizado por deficiência do terço inferior. 
A mesma relatou ter passado por tratamento ortodôntico prévio e o resultado final atingido foi o alinhamento dental, porém, com pouco impacto sobre o perfil facial, sendo indicada uma cirurgia ortognática corretiva para ganho no terço inferior da face menor projeção da maxila e consequente harmonização do perfil. Este procedimento não era considerado pela paciente no momento, devido às limitações decorrentes do mesmo. Assim, foi proposto um tratamento menos invasivo e oneroso, composto por sessões de microagulhamento, aplicação de toxina botulínica tipo A e preenchimento com ácido hialurônico. Após a explicação de todos os prós e contras do tratamento, a paciente autorizou e o mesmo teve início.

Foram realizadas duas sessões de microagulhamento, com rolos de 540 agulhas de $1 \mathrm{~mm}$ e de DMAE Complex (Laboratório de Manipulação Biometil Ltda., São Bento do Sul, SC, Brasil), composto por DMAE 3\% (importante antirrugas), ácido hialurônico $40 \mathrm{mg} / 2 \mathrm{~mL}$ (ajuda na hidratação da pele e estimula a produção de colágeno), silício orgânico $1 \mathrm{mg} / \mathrm{ml}$ (combate a flacidez), ácido alfa lipóico 0,5\% (antioxidante e varredor de radicais livres que aceleram o envelhecimento) e lidocaína $1 \%$ (solução anestésica); com intervalo de 30 dias entre elas. Para tal, a face da paciente foi higienizada com água e sabão e recebeu a aplicação de gel de clorexidina a $2 \%$ (Farmácia de Manipulação Musgo, Alfenas, MG, Brasil). Em seguida, iniciou-se 0 microagulhamento, realizando-se movimentos curtos, nos sentidos horizontais, verticais e diagonais, em todas as áreas da face, exceto pálpebras e lábios ${ }^{12}$. Depois do microagulhamento foi aplicado o DEMAE Complex, a face foi recoberta com gaze estéril e foi feita uma máscara de gelo, com a finalidade de reduzir o edema e o eritema, durante 20 minutos. Após este período, o gelo e a gaze foram removidos, a face foi limpa com solução fisiológica estéril e foi aplicada uma máscara (Farmácia de Manipulação Musgo, Alfenas, MG, Brasil) composta por Fator TGP-2 Pepti 1\%, fator TGF-B3 1\%, nanofactor vitamina C 3\% e sérum revitalizante, agindo por 30 minutos. Após este tempo, a máscara foi removida e as instruções de cuidado foram transmitidas à paciente, incluindo evitar ao máximo exposição solar, a importância do uso de filtro solar, utilizar água termal ou soro fisiológico em caso de incômodo e não ficar tocando na pele onde foi realizado o procedimento. A paciente retornou 20 dias após a última sessão de microagulhamento para registro fotográfico para acompanhamento do tratamento (Figura 2)
Onde pôde ser notada a melhora da textura da pele, uniformização da coloração e atenuação das marcas de expressão finas, tanto em repouso (Figura 2A) quanto nas expressões (Figura 2B-D).

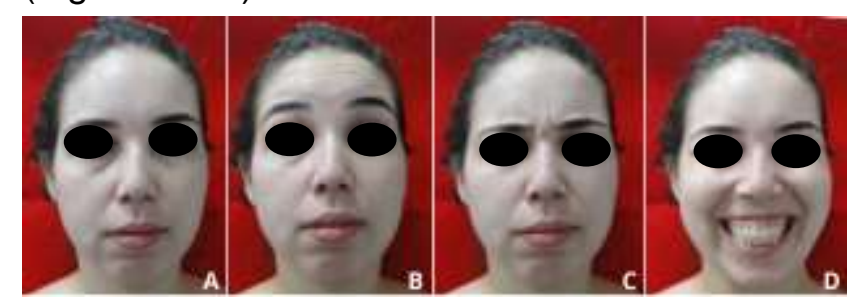

Figura 2 - Registro após a segunda sessão de microagulhamento. A: em repouso. B, C e D: em expressões.

A etapa seguinte consistiu na aplicação da toxina botulínica tipo A (Botulim, Blau Farmacêutica S.A., Cotia, SP, Brasil). Para tal, a toxina foi reconstituída e aplicada seguindo as informações do fabricante. Foram necessárias 53,75 unidades $(U)$, injetadas em pontos específicos nos músculos frontal $(13,75 \mathrm{U})$; prócero (5U) ; corrugadores do supecílio (5U); elevadores do lábio superior (15U); mentual (5U) e região periocular (10U). Todas as orientações foram transmitidas à paciente, incluindo a importância de não massagear as regiões tratadas logo após a aplicação, evitar realizar exercícios físicos intensos por 2 dias após a aplicação, manter-se em posição vertical durante as primeiras 4 horas após a aplicação, evitar exposição solar e a temperaturas extremas e fazer uso de filtro solar; e foi aguardado o período de 15 dias. Passado este período, a paciente foi reavaliada, feito novo registro fotográfico (Figura 3) e notou-se que as linhas de expressão finas bem como o aspecto de casca de laranja do mento haviam desaparecido (Figura 3A); assim como as rugas dinâmicas na região frontal (Figura $3 \mathrm{~B}$ ) e da região periocular (3D), contudo as da região do prócero e corrugadores do supercílio apesar de estarem mais amenas, ainda eram perceptíveis (Figura $3 \mathrm{C}$ ), assim como a exposição gengival ainda era grande (Figura 3D). Dessa maneira, foram aplicadas mais 17,5 unidades da toxina nestas regiões, sendo $10 \mathrm{U}$ no prócero, $5 \mathrm{U}$ nos corrugadores e 2,5U nos elevadores do lábio superior. Em aspecto geral, estas aplicações suavizaram a expressão e a paciente relatou estar satisfeita com o resultado obtido até então. Em seguida, deu-se início ao preenchimento facial com ácido hialurônico (Rennova, Innovapharma, Goiânia, GO, Brasil). Para tal, foram utilizados os preenchedores Rennova ${ }^{\circledR}$ fill, para as olheiras e filtro labial, e Rennova ${ }^{\circledR}$ deep, para o mento. Assim, $0,2 \mathrm{~mL}$ foram aplicados na região das olheiras de cada lado, pela técnica da retroinjeção e usando uma 
cânula de 27G; 0,2mL foi aplicado na região do filtro labial, sendo $0,1 \mathrm{~mL}$ de cada lado, com a própria agulha que acompanha o preenchedor, pela técnica de retroinjeção. No mento foram realizadas duas aplicações de $0,2 \mathrm{~mL}$ cada uma, usando a técnica de bolus. O resultado imediato (Figura 4) foi caracterizado pelo desaparecimento da linha que demarcava a olheira (Figura 4A e B), uma ligeira elevação do filtro labial e a projeção do mento (Figura $4 \mathrm{C} \mathrm{e}$ $D)$, que era o ponto que mais incomodava a paciente. Ao final do procedimento, todas as orientações necessárias foram transmitidas à paciente, incluindo evitar atividades físicas nas primeiras 24 horas, evitar massagear as áreas de aplicação nas primeiras 6 horas, em caso de dor e inchaço fazer compressas geladas por 20 minutos 3 vezes ao dia, hidratar a pele, evitar exposição solar e a temperaturas extremas e usar filtro solar.

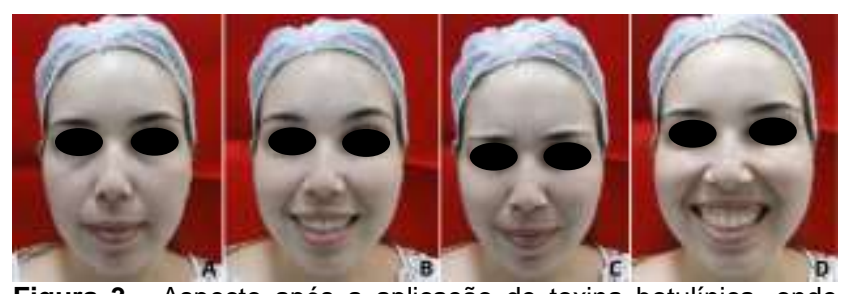

Figura 3 - Aspecto após a aplicação de toxina botulínica, onde pôde ser notado o desaparecimento das marcas de expressão finas e do aspecto de casca de laranja do mento, produzido pela hipertonia do músculo mentual $(A)$ e completo desaparecimento ou atenuação das marcas de expressão dinâmicas na região do frontal (B), do prócero e corrugadores do supercílio (C), da região periorbital (D) e redução da exposição gengival (D)

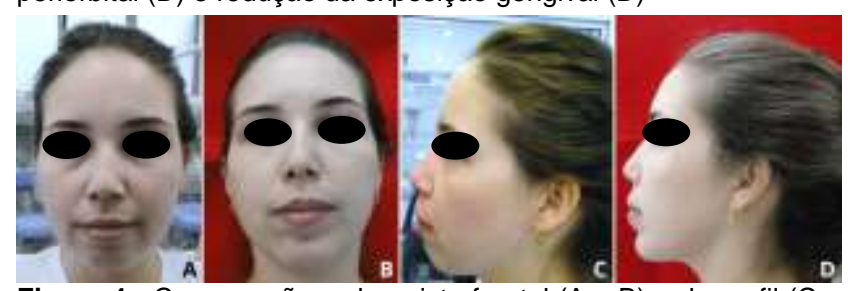

Figura 4 - Comparação, sob a vista frontal (A e B) e de perfil (C e D) do aspecto inicial e final, após a aplicação do preenchedor. Nota-se o preenchimento completo das olheiras (A e B) e ganho no terço inferior da face com o preenchimento do mento (C e D).

DISCUSSÃO

O planejamento de procedimentos que buscam a harmonização facial é complexo tendo em vista as diferenças individuais para a percepção do belo $e$ as características anatômicas de cada paciente, as quais podem limitar os resultados esperados e desejados a partir das terapias empregadas. Com a melhor compreensão, desenvolvimento das técnicas e popularização dos procedimentos estéticos pouco invasivos, o equilíbrio entre as proporções faciais ganhou maior destaque, o que resultou no aumento da necessidade de capacitação e estudo por parte dos profissionais envolvidos neste tipo de tratamento a fim de garantir resultados mais estéticos e naturais aos pacientes ${ }^{13}$.
Tratamentos ablativos têm sido difundidos na dermatologia por muitos anos. Peelings químicos, médios e profundos são utilizados para estimular a produção de colágeno e, assim, melhorar a aparência e a textura, atenuar rugas finas e corrigir cicatrizes da pele. Com o microagulhamento consegue-se estimular a produção de colágeno sem desepitelização total observada nas técnicas dos peeling químicos. Isso se deve ao fato das microlesões provocadas na pele produzirem uma inflamação local que aumenta a proliferação celular e o metabolismo do tecido (derme e epiderme). Essa alteração metabólica gera a síntese de colágeno, elastinas e outras substâncias que restituem a integridade da pele. A técnica do microagulhamento também tem como finalidade abrir microcanais na superfície do tecido, aumentando a permeabilidade e favorecendo a difusão de ativos em maiores concentrações no tecido subcutâneo. Assim, o microagulhamento faz-se útil para o tratamento e eficaz na correção da pele e preparação para outros procedimentos ${ }^{14,15}$. Em função do exposto, esse foi o primeiro tratamento considerado no planejamento da paciente em questão.

Pode-se dizer que a Toxina Botulínica se tornou o procedimento mais popular quando se fala de rejuvenescimento facial por ser amplamente buscada por indivíduos que visam eliminar ou suavizar marcas que se formam com as expressões faciais; além da grande probabilidade de se atingir resultados positivos a partir da sua aplicação e da facilidade de manuseio por parte do profissional. Porém, não se pode ignorar o fato de esta ser uma toxina extremamente potente e quando aplicada incorretamente em músculos mais profundos, ou em regiões como glândulas ou até mesmo mais raramente quando sua injeção ocorre próxima a músculos indesejados, os problemas podem ser graves, como exemplo a ptose palpebral, dificuldade de deglutição e respiração, impedindo sua movimentação normal, podendo, inclusive, levar a óbito. Em casos extremos, sua administração errônea em altas doses pode levar ao paciente a desenvolver sintomas de botulismo, podendo resultar em óbito. Por isso, o FDA ("Food and Drug Administration") determinou que todas as formulações da Toxina Botulínica do Tipo A recebam uma rotulagem preta junto do nome comercial do produto, de modo a alertar sobre uma complicação com risco de morte que é rara, porém potencial; e que pode ocorrer caso haja a difusão do produto por via sistêmica ${ }^{16}$. 
Apesar de o uso do ácido hialurônico na harmonização da face não ser considerado um substituto para a cirurgia plástica por apresentar desvantagens como não ser um tratamento definitivo e, em algumas situações, demandar de várias seções para se obter o resultado desejado, seu emprego vem apresentando destaque devido às vantagens que possui, a saber: é uma opção que não envolve procedimentos altamente invasivos, não demanda de internação hospitalar e, consequentemente, não requer preparo précirúrgico e a recuperação pós-operatória apresenta menor morbidade, é reversível e apresentar menor custo inicial ${ }^{17}$.

O uso desta substância para diversos fins tem aumentado a cada dia, com aplicação em várias regiões da face, como lábios, mento e correção de olheiras. A literatura aponta que, assim como no caso relatado, o preenchimento melhora o aspecto da "depressão" abaixo da órbita e também ajuda na hidratação e, em alguns casos, altera a pigmentação da região preenchida $^{18}$.

Outra técnica de preenchimento de olheiras que vem sendo difundida e extremamente utilizada na Europa, Ásia e Estados Unidos é com a utilização de cânulas, introduzidas por um oríficio resultante de perfuração com agulha (pertuito), próximo à fossa lacrimal ou na região malar. Esta técnica é considerada mais segura e confortável para o paciente e com menor chances de complicações, como hematomas ou traumas. A região periorbital apresenta características anatômicas difíceis para a realização de preenchimento, por ser constituída de pele extremamente fina e muito próxima ao osso e ao globo ocular, ser extremamente vascularizada e pelo risco de cegueira por compressão do nervo óptico decorrente de hematoma retro-bulbar ${ }^{19}$. Divergindo essa opinião, quando cânulas são utilizadas, à medida que o produto é injetado, por ser viscoelástico, vai afastando as estruturas nobres da região, diminuindo a probabilidade de injeção intravascular. Por isso o profissional deve ter uma boa qualificação e entendimento de anatomia para que se amenizem os riscos indesejados ${ }^{2,3,17,18,19}$.

A aparência facial é fundamental para que o paciente se sinta bem, pois está diretamente relacionada a padrões de beleza, uma vez que a face influencia a forma como as pessoas são aceitas ou até mesmo são tratadas na sociedade. Partindo deste pressuposto, entende-se que os indivíduos; para se sentirem mais jovens e, em consequência terem sua autoestima aumentada; buscam cada vez mais por procedimentos estéticos, principalmente faciais. Este fato, aliado ao avanço das técnicas em HOF, correta seleção do material e técnica a serem utilizados e habilidade do profissional, tem promovido que os procedimentos se tornem mais acessíveis, menos dolorosos e mais duradouros para os pacientes ${ }^{20}$.

A partir do exposto, pode-se afirmar que - cirurgião-dentista que pretende realizar tratamentos estéticos relacionados à harmonização orofacial deve ser capaz de reconhecer as alterações passíveis de correção por meio de terapias estéticas não cirúrgicas, e deverá possuir, também, o conhecimento profundo acerca da anatomia da região a ser tratada e dos materiais que serão utilizados, para que o resultado seja obtido conforme o planejado.

CONCLUSÃO

O presente estudo relatou um caso clínico de Harmonização Facial em paciente jovem envolvendo microagulhamento para tratamento prévio da pele, aplicação de toxina botulínica do tipo A para correção do sorriso gengival, relaxamento da musculatura do mento e suavização de rugas de expressão dinâmicas; e preenchimento de mento e deformidade do canala lacrimal com ácido hialurônico. Concluiu que as técnicas aplicadas foram efetivas para os fins propostos, para reestabelecer os padrões normais e harmônicos relacionados ao biotipo e às queixas apresentadas pela paciente.

\section{AGRADECIMENTOS}

Agradecemos ao Ministério da Educação (MEC) pelo fomento do presente trabalho através da concessão de bolsa pelo Programa de Educação Tutorial (PET-Odontologia da UNIFAL-MG).

REFERÊNCIAS

1. Garbin A, Wakayama B, Saliba TA, Garbin CAS. Harmonização orofacial e suas implicações na odontologia. BJSCR. 2019;27: 116-22.

2. Almeida AT, Banegas $R$, Boggio $R$, et al. Diagnóstico e tratamento dos eventos adversos do ácido hialurônico: recomendações de consenso do painel de especialistas da América Latina. Surg Cosmet Dermatol. 2017; 9:204-13.

3. Maio, M. Desvendando os códigos para rejuvenescimento facial: uma abordagem passo a passo para uso de injetáveis. 1. Ed., São Paulo: Allergan; 2015. 97 p.

4. Paulo EV, Oliveira RCG. Avaliação e sugestão de protocolo estético para aplicação de toxina botulínica do tipo a em pacientes 
adultos. Revista UNINGÁ. 2018;55:158-67.

5. Conselho Federal de Odontologia. Resolução 198 de 29 de janeiro de 2019. Disponível em http://sistemas.cfo.org.br/visualizar/atos/RESOL U\%C3\% 87\%C3\%83\%/SEC/2019/198.

6. Pereira BB, Terruel DS, Carrillo MFB. Tratamento das cicatrizes atróficas de acne por meio do microagulhamento com equipamento dermapen em mulheres entre 20 a 30 . Rev Cient Unisalesiano. 2016;7:232-47.

7. Dall'Magro AK, dos Santos R, Dall'Magro E, Flor B, Matiello CN, de Carli JP. Aplicações da toxina botulínica em Odontologia. Salusvita. 2015,34:371-82.

8. Schlosser DV. Santos MA, da Silva, PG, et al. Uso da toxina botulínica na Odontologia. Rev Gestão \& Saúde. 2016;15:26-34.

9. Balassiano LKA, Bravo BSF. Hialuronidase: uma necessidade de todo dermatologista que aplica ácido hialurônico injetável. Surg Cosmet Dermatol. 2014;6:338-43.

10. da Silva LD, Alencar DS, de Souza ET, da Silva BF, Freitas LCB. Tratamento do perfil facial com retrusão da mandíbula, aplicando ácido hialurônico após tratamento ortodôntico - relato de caso. Braz J Surg Clin Res. 2018;25:76-80.

11. Moreira Jr R, Ribeiro PD, Condezo AFB, Cini MA, de Antoni CC, Moreira R. Fundamentos da análise facial para harmonização estética na odontologia brasileira. Clín Pesq Odontol UNITAU. 2018;9:59-65.

12. Albano RPS, Pereira LP, Assis LB. Microagulhamento - A terapia que induz a produção de colágeno - Revisão de literatura. Rev Saúde em Foco. 2018; 10:455-73.

13. Sant'Ana E, Kuriki EU, Arnett W, Lautenschlager GAC, Yaedu RYF. Avaliação comparativa do padrão de normalidade do perfil facial em pacientes brasileiros leucodermas e em norte-americanos. Rev Dent Press Ortod Ortop Facial. 2009;14:80-9.

14. Lima EVA, Lima MA, Takano D. Microagulhamento: estudo experimental e classificação da injúria provocada. Surg Cosmet Dermatol. 2013;5:110-4.

15. Kayn AP, Limana MD, Moraes LRS. Microagulhamento como agente potencializador da permeação de princípios ativos corporais do tratamento de lipodistrofia localizada. VIII EPCC-Encontro internacional de Produção Cientifica Cesumar .2013. ISBN 978-85-8084-603-4.

16. Silva JFN. A aplicação da Toxina Botulínica e suas complicações. Revisão Bibliográfica. 2012. 154f. Dissertação (Mestrado em Medicina Legal) - Universidade do Porto, Portugal. 2012.

17. Gutowski KA. Hyaluronic acid fillers. Clin Plast Surg. 2016;43:489-96.
18. Lee D, Lu Q, Sommerfeld SD, et al. Targeted delivery of hyaluronic acid to the ocular surface by a polymer-peptide conjugate system for dry eye disease. Acta Biomat. 2017;55:163-71.

19. Coimbra DDA. Preenchimento dos sulcos orbital inferior e naso-jugal com ácido hialurônico de baixa concentração: uma nova técnica de aplicação. Surg Cosmet Dermatol. 2010;2:67-70.

20. Thome L, Lins A, Amorim J. O uso do ácido hialurônico e toxina botulínica na harmonização orofacial: Revisão de literatura. Rev Cathedral. 2020;2:103-10.

\section{CONFLITO DE INTERESSES}

Os autores declaram não haver conflitos de interesse

AUTOR PARA CORRESPONDÊNCIA

\section{Marcela Filié Haddad}

Faculdade de Odontologia, Universidade Federal de Alfenas (UNIFAL-MG)

Rua Gabriel Monteiro da Silva, 700, Centro,

37.130-000 Alfenas - MG, Brasil

Telefone: (35) 3299-1464,

E-mail:marcela.haddad@unifal-mg.edu.br

Submetido em 13/07/2021

Aceito em 23/09/2021 